\title{
Topical microbicides for the prevention of sexually transmitted diseases and HIV
}

\author{
André Désormeaux PhD, Rabeea F Omar PhD, Michel G Bergeron MD FRCP
}

\begin{abstract}
A Désormeaux, RF Omar, MG Bergeron. Topical microbicides for the prevention of sexually transmitted diseases and HIV. Can J Infect Dis 1999;10(Suppl C):41C-48C.

The development of novel compounds to reduce the sexual transmission of human immunodeficiency virus (HIV), herpes and other pathogens causing sexually transmitted diseases (STDS) has become a topic of great interest. Condom use is the only readily available measure to reduce successfully the propagation of these infectious agents. To reduce significantly the probability of acquiring infection, condoms should be used during all risky sexual intercourse. More attention is being given to female-controlled methods for the prevention of HIV infection because many women are unable to negotiate condom use with their sexual partners. The development of topical microbicides constitutes one of the most prioritized research areas in the field of prevention of STDs/HIV for the World Health Organization, the National Institutes of Health and the Centers for Disease Control and Prevention. Because the number of women infected with HIV, herpes and other pathogens causing STDs is growing dramatically worldwide, there is an urgent need to develop innovative preventive measures that can reduce the transmission of these pathogens with minimal mucosal irritation, and minimal effects on the vaginal flora and $\mathrm{pH}$. Some of the existing products as well as promising new topical microbicides for the prevention of sexually transmitted infections are reviewed.
\end{abstract}

Key Words: Human immunodeficiency virus; Prevention; Sexually transmitted diseases; Topical microbicides

\begin{abstract}
Microbicides topiques dans la prévention du VIH et des maladies transmises sexuellement
RÉSUMÉ : La mise au point de nouveaux composés pour réduire la transmission sexuelle du virus de l'immunodéficience humaine (VIH), de l'herpès et des autres pathogènes causant les maladies transmises sexuellement (MTS) est devenue un sujet de grand intérêt. L'utilisation du préservatif est la seule mesure d'accès facile qui permet de réduire la propagation de ces agents infectieux. Pour réduire de façon significative la probabilité d'une infection, les préservatifs devraient être utilisés pendant tous les rapports sexuels à risque. On se penche de plus en plus sur des méthodes de prévention contre l'infection à VIH contrôlées par les femmes parce que ces dernières sont nombreuses à ne pas pouvoir négocier l'utilisation du préservatif avec leurs partenaires sexuels. La mise au point de microbicides topiques constitue l'une des priorités dans le domaine de la recherche sur la prévention du VIH et des MTS pour l'Organisation mondiale de la santé, les National Institutes of Health et le Center for Disease Control and Prevention. Parce que le nombre de femmes infectées par le VIH, l'herpès et d'autres pathogènes causant les MTS ne cesse de s'alourdir à travers le monde, il faut d'urgence développer des mesures préventives innovatrices qui peuvent réduire la transmission de ces pathogènes en garantissant une irritation minimale des muqueuses et des effets minimaux sur la flore vaginale et le $\mathrm{pH}$. Certains des produits existants de même que de nouveaux microbicides topiques prometteurs pour la prévention des infections transmises sexuellement sont passés en revue.
\end{abstract}

Centre de Recherche en Infectiologie, Université Laval, Ste-Foy, Québec

Correspondence and reprints: Dr MG Bergeron, Centre de Recherche en Infectiologie, CHUQ, Pavillon CHUL, 2705 boul Laurier, RC-709, Ste-Foy, Quebec G1V 4G2. Telephone 418-654-2705, fax 418-654-2715, e-mail Michel.G.Bergeron@crchul.ulaval.ca 
$\mathrm{T}$ he spread of infectious diseases caused by the sexual transmission of human immunodeficiency virus (HIV), herpes and other pathogens causing sexually transmitted diseases (STDs) is growing at a bewildering rate. The global incidence, morbidity and mortality of STDs are very significant. It is estimated that several hundred million individuals worldwide are infected with pathogens causing STDs, and each year more than 12 million people in the United States are newly infected with pathogens responsible for STDs (1). Globally, more than 330 million new cases of STDs (excluding those caused by HIV) occur each year (2). Neisseria gonorrhoeae and Chlamydia trachomatis are recognized as two of the most prevalent sexually transmitted bacterial infections. Worldwide, there is an estimated annual incidence of 25 million cases of gonorrhoea and 50 million cases of chlamydia. Chlamydia is a major cause of pelvic inflammation in women, leading to infertility and ectopic pregnancy, and can result in conjunctivitis and pneumonia in newborn infants exposed during passage through an infected birth canal (3). Recent epidemiological data indicate that the number of individuals infected with HIV is growing dramatically throughout the world. According to United Nations officials, epidemiological data suggest that in 1997 as many as 16,000 individuals became infected with HIV each day (4). HIV infection is now the sixth leading cause of death among persons 15 to 24 years of age in the United States (5). In 1996, AIDS was the leading cause of death among African American women 25 to 44 years of age (2). Recent statistics (as of the end of 1998) from the World Health Organization (WHO) indicated that there are about 34.6 million people infected with HIV worldwide, and this number is projected to reach 40 million by the year 2000 .

Herpes simplex virus type-1 (HSV-1) and type-2 (HSV-2) are the most common infective causes of genital ulceration in developed countries. Genital herpes infection is lifelong and may result in painful and recurrent genital lesions, systemic complications, psychosocial morbidity and rare but serious neonatal diseases following intrapartum transmission of HSV (6). Genital transmission of this pathogen is usually due to asymptomatic viral shedding by people who are unaware that they are infected. HSV-2 is now detectable in one of five Americans 12 years of age or older (7). In addition, it is estimated that over one-third of the world's population has recurrent HSV infections and, therefore, has the capability to transmit the virus during episodes of productive infection. Improvements in the prevention of HSV-2 infection are needed because genital ulcers may facilitate HIV transmission. An important risk of genital HSV infection is the subsequent exposure of neonates when the mother is clinically symptomatic for primary infection. Neonates acquire the infection most commonly intrapartum or during birth. Neonates may present infection localized to the skin, eyes and mucosa, or the central nervous system. Disseminated neonatal HSV is also possible. If untreated, the mortality rate from neonatal HSV infection is $70 \%$.

Transmission of HIV from an infected mother to her infant is the major route of acquisition of this infection in children. The consequences of HIV transmission on infant and maternal health, family and society are enormous. Mother to child transmission of HIV is a significant problem in countries with endemic HIV infection. Each year, an estimated 300,000 babies worldwide are born infected with HIV due to perinatal transmission (8). The frequency and risk factors for HIV transmission from mother to child have been investigated in a cohort of 365 children of HIV-infected mothers and 363 control children in Kenya. The overall risk of transmission from mother to child was estimated to be $42.8 \%$ (9). A substantial proportion of infection occured postnatally, possibly through breastfeeding. It has been postulated that the HIV pandemic will kill three million or more women and children during the 1990s. Therefore, to control the epidemic, there is a very urgent need to develop strategies to prevent the sexual transmission of HIV, particularly in developing countries where the community cannot afford appropriate treatments. Preventive measures aimed at blocking the initial transmission of pathogens that are the causative agents of AIDS, herpes and other STDs will lead, of course, to enormous benefits.

of the estimated 7000 new HIV infections occuring throughout the world each day, it is estimated that between $85 \%$ and $90 \%$ are the result of heterosexual transmission $(2,10)$. More information is known about the mechanisms of sexual transmission of HIV. Figure 1 depicts a general schematic representation of the sexual transmission of HIV. Initially, free or cell-associated virus in semen must gain entry through a mucosal surface to infect target cells, presumably macrophages and Langerhans cells $(11,12)$. Afterwards, infected cells migrate through lymphatic vessels to the draining lymph nodes, where virus replicates actively. It has been estimated that the number of viral particles present in an entire lymph node may be as high as $1.2 \times 10^{9}$ particles $/ \mathrm{cm}^{3}(13)$. The high viral load observed in the lymphoid tissues was reported to be partially associated with trapped HIV particles on the follicular dendritic cells (FDC) located in the germinal centres (13-15). In addition to the extracellular localization of HIV in interdendritic spaces of germinal centres, viral particles were also found within the endosomal and cytoplasm compartments of FDC (16). Over the course of HIV infection, the FDC network was shown to be gradually disrupted and ultimately destroyed. The incapacity of FDC to retain HIV particles in advanced stages of the disease has been postulated to contribute to the increased viral burden in the periphery (17).

Because there is no vaccine against HIV, preventive measures are the only tools that can presently reduce the transmission of this retrovirus. The consistent and careful use of condoms is an effective barrier against the sexual transmission of HIV and other pathogens causing STDs, but they should be used in all risky sexual intercourse to reduce significantly the probability of acquiring infection. In Africa, the most intensive prevention programs were only able to increase condom use to approximately $70 \%$ of all sexual intercourse in female prostitutes (18). Consequently, doubts have arisen about the possibility of condom promotion in controlling the AIDS epidemic in high risk groups. The situation may be similar in homosexual men from developed countries, where relapse to unsafe sexual practices, including lack of condom use 


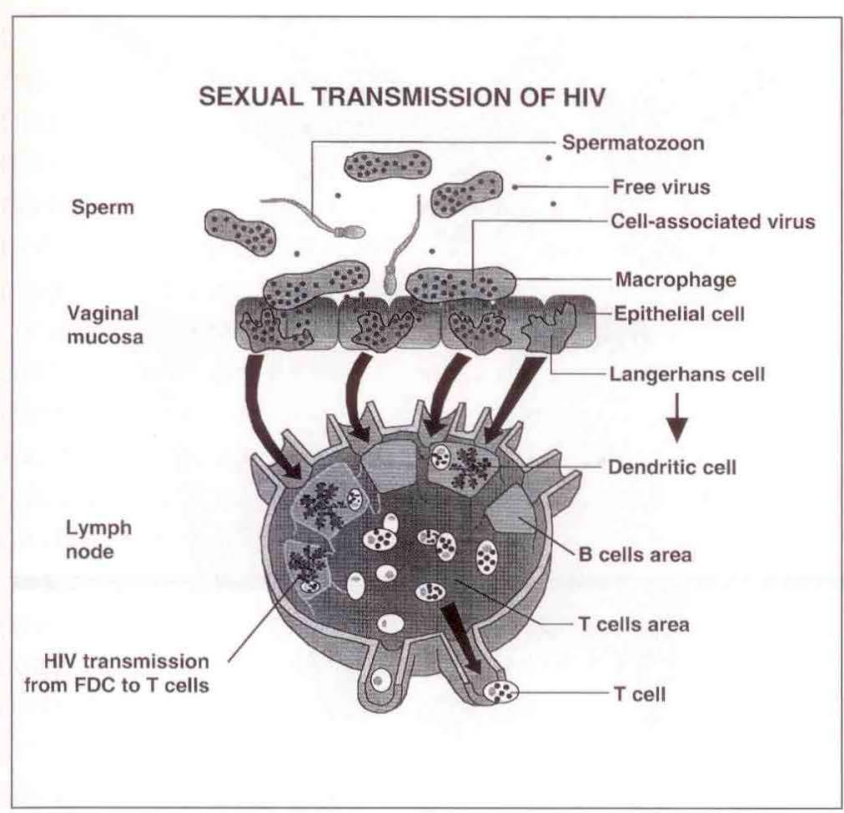

Figure 1) Schematic representation of the sexual transmission of human immunodeficiency virus (HIV). FDC Follicular dendritic cells

for anal intercourse, has been documented in several studies $(19,20)$. More attention has recently been given to femalecontrolled methods for the prevention of HIV infection because many women are unable to negotiate condom use with their partners $(21,22)$. In situations where heterosexual transmission of HIV is of concern, preventive measures where women can protect themselves against STDs may be an additional tool to control the epidemic $(21,23-26)$. Such a protective tool may also be used in male homosexual relations because it may provide additional protection that is under the control of the receptive partner. Therefore, it is important to develop barrier methods that can be used as an alternative to condom use where the person is able to control her or his own protection without having to ask their sexual partner.

\section{MECHANISMS OF ACTION OF MICROBICIDES}

The development of safe topical microbicides is a very high priority in the field of prevention of STDs and HIV for the WHO, the National Institutes of Health $(\mathrm{NIH})$ and the Centers for Disease Control and Prevention. A topical microbicide is often composed of an active ingredient and a vehicle. Table 1 summarizes the various mechanisms of action of microbicides. Active ingredients may act via a variety of mechanisms, including disrupting the organism's cell membrane or envelope (eg, detergent-type spermicides/microbicides such as nonoxynol-9), blocking the receptor-ligand interactions essential for infectivity (eg, microbial adhesion inhibitors such as sulphated compounds), inhibiting the intracellular or extracellular replication of the pathogen ( $\mathrm{eg}$, antimicrobial drugs), altering the vaginal environment and reducing susceptibility to infection (eg, buffering agents and products that maintain normal vaginal flora and environment) or enhancing local immune responses (eg, immune response modifiers) (27). The overall efficacy of a topical microbicide against the
TABLE 1

Summary of various mechanisms of action of microbicides

\begin{tabular}{lcc} 
Mechanism of action & $\begin{array}{c}\text { Category of } \\
\text { active ingredient }\end{array}$ & $\begin{array}{c}\text { Example of active } \\
\text { ingredient }\end{array}$ \\
\hline $\begin{array}{l}\text { Disruption of the organism's } \\
\text { cell membrane or } \\
\text { envelope }\end{array}$ & $\begin{array}{c}\text { Detergent-type } \\
\text { spermicides/ } \\
\text { microbicides }\end{array}$ & Nonoxynol-9 \\
$\begin{array}{l}\text { Blockage of the receptor- } \\
\text { ligand interactions } \\
\text { essential for infectivity }\end{array}$ & $\begin{array}{c}\text { Microbial } \\
\text { adhesion } \\
\text { inhibitors }\end{array}$ & Dextran sulphate \\
$\begin{array}{c}\text { Inhibition of the intracellular } \\
\text { or extracellular replication } \\
\text { of the pathogen }\end{array}$ & $\begin{array}{c}\text { Antimicrobial } \\
\text { drugs }\end{array}$ & AZT, 3TC, indinavir \\
(against HIV)
\end{tabular}

AZT 3'-azido-3'deoxythymidine; HIV Human immunodeficiency virus; 3TC 2',3'-didoxy-3'-thiacytidine

sexual transmission of pathogens causing STDs depends on the efficacy of the active ingredient to be delivered and its ability to cover the entire vaginal/cervix area for maximal efficacy against pathogens. The capacity of these active agents to cover the entire vaginal cavity depends highly on the type of vehicle used. Typical formulations of vehicles include gels, creams, foams, suppositories, sponges and films (21). Some of the most common problems associated with the use of topical microbicides are summarized.

\section{ACTIVE INGREDIENTS}

Spermicides, such as the nonionic surfactant nonoxynol-9, are common active ingredients used as intravaginal products to prevent pregnancy and sexual transmission of infectious agents. These products chemically destroy micro-organisms by disrupting their outer membrane and limiting infectivities. However, one major problem associated with the use of such spermicides is that they can induce local inflammation and ulceration of the vaginal and cervical mucosae, which may favour the entry of pathogens rather than protecting against them. Nonoxynol-9 remains the most commonly used spermicide/microbicide worldwide. However, the toxicity of nonoxynol-9 for mucosal tissues is well documented and is intimately associated with the frequency of its use. Laboratory results have shown that intravaginal application of $125 \mathrm{mg}$ nonoxynol-9 once daily for two weeks in rabbits was very toxic to the vaginal and cervical mucosae compared with controls (Figure 2a,c).

Toxicity studies: Niruthisard et al (28) conducted a single phase I local toxicity study of the effects of frequent insertion of $150 \mathrm{mg}$ nonoxynol-9 vaginal suppositories on the lower genital tract. Epithelial disruption of the cervix and vagina occurred in $43 \%$ of women using this formulation qid for 14 days. 


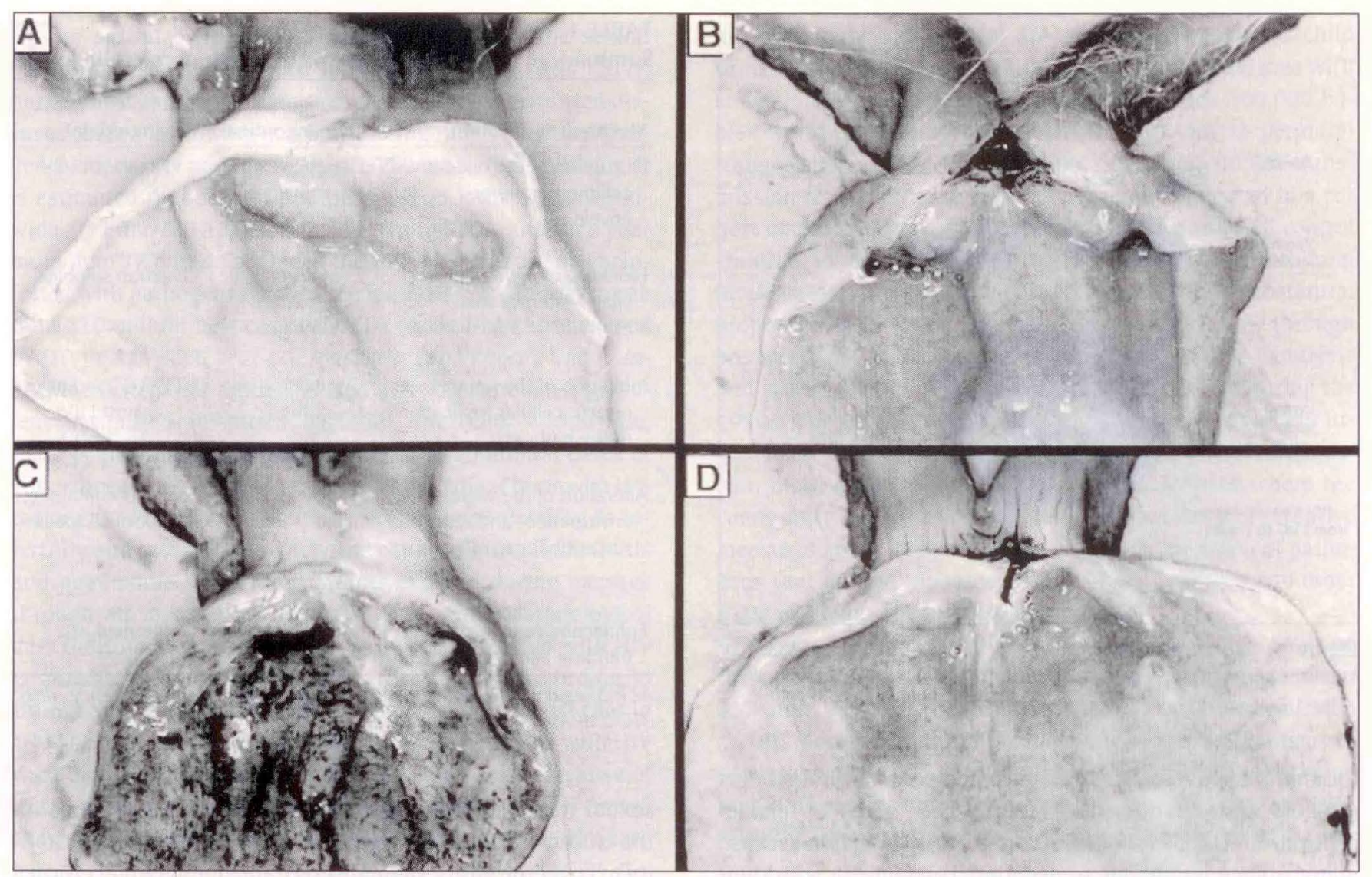

Figure 2) Photographs of the genital mucosae of female New Zealand rabbits after 14 days of daily treatment with a) buffer (control), b) thermoreversible gel, c) $125 \mathrm{mg}$ of nonoxynol-9 or d) $125 \mathrm{mg}$ of nonoxynol-9 incorporated into the thermoreversible gel. Photographs are representative of all treated animals ( $n=3$ to 4 per group)

Another randomized study conducted in healthy women has shown that nonoxynol-9 has a dose-response effect on cervical epithelial disruption (29). In another study, nonoxynol-9 used for seven days in a standard spermicidal dose $(100 \mathrm{mg})$ was associated with increased irritation, and colposcopic and histological evidence of inflammation in the genital tract, and was more frequently associated with reduction in numbers of lactobacilli (30). A recent safety evaluation study including 534 women at low risk of infection with HIV showed that daily application of a gel containing only $52.5 \mathrm{mg}$ nonoxynol-9 for 14 days showed low toxicity (31). A safety study conducted in 60 female sex workers in Kenya using a polymer-based gel containing $52.5 \mathrm{mg}$ nonoxynol-9 also showed no major genital epithelial toxicity of the spermicidal vaginal gel (32). However, more trials on the efficacy of these products must be conducted among women at high risk of infection to evaluate fully their potential as topical microbicides. On the other hand, a randomized, placebo controlled safety study performed in 125 prostitutes in Senegal showed that frequent use of tablets containing $60 \mathrm{mg}$ of the spermicide menfegol also resulted in high incidence of genital lesions, and it was suggested that their frequent use to prevent HIV transmission should not be recommended (33).

Disruption of vaginal flora: Lactobacillus species are the predominant organisms in the vaginal flora of healthy women. They are believed to maintain the vaginal flora eco- system by maintaining low vaginal $\mathrm{pH}$ and producing hydrogen peroxide $\left(\mathrm{H}_{2} \mathrm{O}_{2}\right)$. Lactobacilli producing hydrogen peroxide may help to protect the female genital tract from acquiring pathogens. Unfortunately, spermicides/microbicides may modify the healthy vaginal flora, thereby favouring the transmission of infectious agents. Many in vitro studies have shown that nonoxynol-9 inhibits the growth of lactobacilli (34-37). Richardson et al (38) recently performed a randomized, double-blind, placebo controlled crossover trial to evaluate the effect of nonoxynol-9 use on vaginal lactobacilli and bacterial vaginosis. Results showed that intravaginal application of a gel containing $52.5 \mathrm{mg}$ of nonoxynol-9 gel once daily for 14 days did not adversely affect vaginal colonization by hydrogen peroxide- producing lactobacilli, but that such use may promote the loss of non-hydrogen peroxide-producing strains. On the other hand, a recent placebo controlled clinical study performed in healthy female volunteers showed a decrease in lactobacilli in $56 \%$ of women using nonoxynol-9 (39). In addition, women with reduced lactobacilli were less likely to regain normal flora than were women whose lactobacilli were unaffected, possibly increasing susceptibility to urinary and gynecological infections.

Efficacy studies: Numerous studies have shown that spermicides are effective in vitro against numerous sexually transmitted pathogens, including HIV (40-49). However, their 
in vivo efficacy against the sexual transmission of HIV is rather controversial. A cohort study conducted involving 273 female sex workers in Cameroon reported a lower rate of HIV infection among women using vaginal suppositories containing $100 \mathrm{mg}$ of nonoxynol-9 (50). In contrast, a randomized, placebo controlled trial in 138 HIV-seronegative women prostitutes in Kenya showed that a nonoxynol-9 sponge was not effective in reducing the risk of HIV infection (51). In this study, it was reported that genital ulcers and vulvitis occurred more frequently in nonoxynol-9 sponge users and that the spermicidal sponge should not be used by women with a high risk of exposure to HIV and/or other pathogens causing STDs. on the other hand, a cohort study conducted among 110 discordant couples in Zambia, where only the man was HIVpositive, did not provide compelling data on the impact of nonoxynol-9 use on risk of HIV infection (52). Finally, a recent controlled trial conducted among 1292 HIV-negative female sex workers in Cameroon showed that the use of a vaginal film containing $70 \mathrm{mg}$ of nonoxynol-9 inserted vaginally before intercourse did not reduce the rate of new HIV, gonorrhoea or chlamydia infection (53). In this study, the rates of HIV infection (cases per 100 woman-years) were 6.7 in the nonoxynol group and 6.6 in the placebo group. In addition, as expected, there was an increase in genital ulcers in the nonoxynol-9 group.

\section{VEHICLES FOR MICROBICIDES}

The failure of nonoxynol-9-based intravaginal products in reducing the transmission of infectious agents may be attributable to the occurrence of mucosal toxicity favouring infection with micro-organisms and the use of an inappropriate vehicle for the delivery of the spermicide/microbicide. Table 2 summarizes the most common vehicles used for topical microbicides.

Vaginal contraceptive film: The vaginal contraceptive film (VCF) is a small, $5 \times 5 \mathrm{~cm}$, paper thin, polyvinyl, alcohol-based formulation that requires no applicator (53). The VCF is inserted intravaginally, where it dissolves within 2 to 5 mins. It has the advantage of being neat, easy to conceal and unaffected by heat. Although convenient, the most important drawback associated with its use is that the film may not fully dissolve and, when dissolved, it may not cover the entire vagina/cervix area to assure maximal protection against infectious agents. In a recent study, the use of a vaginal film containing $70 \mathrm{mg}$ of nonoxynol-9 failed to protect against HIV, gonorrhoea and chlamydia (53). The toxicity associated with high nonoxynol-9 concentration did not seem to cause the lack of protection. There may be several reasons for the lack of protection by the vaginal film. Nonoxynol-9 may have been rapidly eliminated or absorbed so that it did not last long enough to protect against STDs, the vaginal film may have not been used properly by subjects, the film may not have covered the whole vaginal and cervical area for proper protection, or this formulation or method of nonoxynol-9 delivery may not have been ideal. The choice of vehicle is very important for the efficacy of the topical microbicide formulation.

Vaginal sponge: Sponges are generally made of polyurethane
TABLE 2

Summary of the most common vehicles for topical microbicides

\begin{tabular}{|c|c|c|}
\hline Vehicle & Advantages & Disadvantages \\
\hline \multirow[t]{3}{*}{ Film } & Not messy & Tends to stick to fingers \\
\hline & Easy to conceal & $\begin{array}{l}\text { Fairly long wait for it to melt } \\
\text { before intercourse }\end{array}$ \\
\hline & & $\begin{array}{l}\text { May not cover the entire } \\
\text { vagina/cervix area }\end{array}$ \\
\hline \multirow[t]{3}{*}{ Sponge } & $\begin{array}{l}\text { Effective immediately } \\
\text { after its insertion }\end{array}$ & $\begin{array}{l}\text { May not cover the entire } \\
\text { vagina/cervix area }\end{array}$ \\
\hline & & $\begin{array}{l}\text { Awkward feeling when } \\
\text { inserted }\end{array}$ \\
\hline & & $\begin{array}{l}\text { Difficult to conceal or } \\
\text { dispose of }\end{array}$ \\
\hline \multirow[t]{3}{*}{ Suppository } & $\begin{array}{l}\text { Small } \\
\text { Easy to conceal }\end{array}$ & $\begin{array}{l}\text { Melts at ambient } \\
\text { temperatures }\end{array}$ \\
\hline & & Causes messy discharges \\
\hline & & $\begin{array}{c}\text { May not cover the entire } \\
\text { vagina/cervix area }\end{array}$ \\
\hline \multirow[t]{3}{*}{$\mathrm{Gel} / \mathrm{cream}$} & Bioadhesive (to mucosae) & May leak out of the vagina \\
\hline & $\begin{array}{c}\text { Stays several hours in } \\
\text { vagina }\end{array}$ & $\begin{array}{l}\text { Applicator difficult to } \\
\text { conceal or dispose of }\end{array}$ \\
\hline & $\begin{array}{l}\text { May cover the entire } \\
\text { vagina/cervix area }\end{array}$ & \\
\hline
\end{tabular}

and contain spermicidal agents along with preservative agents (54). The sponge has a diameter of about $5.5 \mathrm{~cm}$ and is $2.5 \mathrm{~cm}$ thick. A loop is attached to the sponge to facilitate its removal. The sponge is inserted intravaginally in a manner similar to that of a diaphragm and is effective immediately after its insertion. A controlled clinical trial conducted in Nairobi showed that a nonoxynol-9-containing vaginal sponge did not reduce HIV transmission in female prostitutes (51). Although the vaginal sponge may be convenient for contraceptive purposes, its ability to offer protection against the sexual transmission of pathogens has yet to be documented.

Suppositories: Although vaginal suppositories are small and easy to conceal, they tend to melt at warm ambient temperatures. They also create a lot of messy discharge, which may make them less appealing to users. This type of vehicle, once melted, may not cover the whole vagina and cervix, and, therefore, its usefulness protecting users against sexually transmitted pathogens is doubtful.

Gels/creams: There are a few products on the market that use nonoxynol-9 in a vaginal gel/cream vehicle. This type of vaginal gel is generally comprised of a polymer (such as carbomer 934) containing a spermicide/microbicide (such as nonoxynol-9). Such products are primarily used as contraceptives, but some formulations are being clinically investigated for their capacity to protect against STDs. No in vitro or animal data have been published to show the efficacy of these vehicles. The marketed formulations (now contraceptives) are gel products delivered via a vaginal applicator, which only delivers the formulations to the cervix area (apical delivery). The gel 
TABLE 3

Important key and desired characteristics of ideal topical microbicides for the Food and Drug Administration (FDA), National Institutes of Health (NIH) and clientele

\begin{tabular}{lc}
$\begin{array}{c}\text { Key characteristics } \\
\text { (FDA/NIH) }\end{array}$ & $\begin{array}{c}\text { Desired characteristics } \\
\text { (clientele) }\end{array}$ \\
$\begin{array}{c}\text { Colourless, odourless, tasteless, } \\
\text { nonstaining }\end{array}$ & $\begin{array}{c}\text { Prevention of STDs/HIV and/or } \\
\text { pregnancy }\end{array}$ \\
$\begin{array}{l}\text { Cover the whole vagina/cervix } \\
\text { condom }\end{array}$ & $\begin{array}{c}\text { Safe, causes no discomfort } \\
\text { Resistant to elution by aqueous } \\
\text { flow } \\
\text { pH similar to that of a healthy } \\
\text { vagina }\end{array}$ \\
$\begin{array}{c}\text { Does not affect normal vaginal } \\
\text { flora }\end{array}$ & Does not reduce sensation \\
Reduces toxicity of microbicides & Easy to use and insert \\
\hline
\end{tabular}

HIV Human immunodeficiency virus; STDs Sexually transmitted diseases

formulation normally stays in the vagina for several hours but generally less than $24 \mathrm{~h}$ with all the vaginal secretions. Unless the gel or cream adheres to the vaginal/cervical mucosae, it may leak out of the vagina with the effect of gravity. There are doubts that the delivered gel will cover the whole vagina/cervix (using a conventional vaginal applicator), which is a key factor for protection against STDs.

In general, vehicles such as film, gel/cream or suppository greatly reduce the irritation caused by spermicides/ microbicides when used frequently, but they all share the existing problem of not showing satisfactory efficacy. Nevertheless, Dr Penelope Hitchcock, chief of the STD branch of the United States National Institute of Allergy and Infectious Diseases at the NIH is very optimistic for the future, because existing products containing the spermicide nonoxynol-9 continue to be tested against STDs and HIV, and new ways to prevent STDs and HIV infection are progressing to early clinical trials (55).

\section{TOPICAL MICROBICIDES UNDER INVESTIGATION}

It is well recognized among developers of topical microbicides that several problems with their use exist. Problems are generally associated with toxicity of microbicides, lack of efficacy and protection against pathogens, and inappropriate vehicles used to deliver them. Scientists who are working on the development of new topical microbicides have focused on two main objectives: to find new effective and nontoxic microbicides, and to find new vehicles that deliver microbicides more efficiently that are also able to reduce the toxicity of existing microbicides. Ideal and safe topical microbicides should inactivate infectious agents with minimal toxicity to vaginal/ cervical mucosae while adhering to mucosal surfaces. The following key characteristics, summarized in Table 3, are considered by both the United States Food and Drug Administration and NIH as important for ideal and safe topical microbicides. They should:

- be colourless, odourless, tasteless and nonstaining;
- cover the whole vagina/cervix, be compatible with male latex condoms and resistant to elution by aqueous flow;

- have a pH (pH 4.0 to 4.5 ) similar to that of a healthy vagina;

- not affect the normal vaginal flora, especially Lactobacillus species; and

- reduce the toxicity of potent spermicides/microbicides such as nonoxynol-9.

Furthermore, ideal microbicides should have the following desirable characteristics for clientele. They should:

- $\quad$ prevent STDs/HIV and/or pregnancy;

- be safe and cause no discomfort;

- be effective right away and remain effective for hours;

- not reduce sensation;

- be easy use and insert;

- be under the user's control; and

- be easy to conceal or dispose of.

The most promising formulations that are highly spoken of and recognized by the NIH are discussed below. These topical microbicides are under active study and are not yet available. BufferGel: BufferGel is a negatively charged, nonabsorbable, high molecular weight polymer gel (carbomer 934) included in the rim of a cervical cup. It has high buffering capacity and maintains natural low vaginal $\mathrm{pH}$ in the presence of semen. Furthermore, it inactivates sperm and kills pathogens. Results from studies on the safety and tolerability of BufferGel were recently presented at the 1998 International Conference on AIDS in Geneva, Switzerland (56). It was concluded that BufferGel, used either once or twice daily, was nontoxic and welltolerated by 38 low risk or sexually active monogamous women. Signs and symptoms associated with product use tended to be local and superficial, and did not result in discontinuation. In addition, this vaginal microbicide was able to maintain a low vaginal $\mathrm{pH}$ in $93 \%$ of 82 determinations. Further studies are under way to assess the safety and tolerability of this product in women in Africa and Asia.

PRO 2000: PRO 2000 topical gel is a $5 \mathrm{kD}$ naphthalene sulphonate polymer that is highly water soluble and virtually colourless, odourless and compatible with latex condoms. PRO 2000 was shown to bind to CD4 with nanomolar affinity and suppress infection by a broad range of HIV isolates in vitro (57). Vaginal gels containing up to $4 \%$ of the polymer were found to be safe and well tolerated in phase I clinical trials involving healthy, sexually abstinent volunteers (58). In another study, PRO 2000 was evaluated for activity against common STD pathogens and for toxicity towards normal vaginal lactobacilli (59). Results showed activity of PRO 2000 against HSV-1, HSV-2 and human cytomegalovirus in vitro. It has also been reported that PRO 2000 topical gel prevented infection of Hela cells by $C$ trachomatis elementary bodies and that this 
product, at a concentration of $1 \mathrm{mg} / \mathrm{mL}$, was not cidal toward N gonorrhoeae, Trichomonas vaginalis and Lactobacillus crispatus. On the other hand, intravaginal application of $4 \%$ PRO 2000 gel to mice 5 mins before infection with HSV-2 protected animals from infection. A reduced protection against vaginal HSV-2 infection was, however, observed when the gel was applied 60 mins before infection. PRO 2000 is presently under further clinical studies.

Thermoreversible gel: A gel formulation (the Invisible Condom) that could be applied to the vaginal, cervical or anorectal mucosae has recently been developed, which may be effective against sexually transmitted pathogens. One paramount characteristic of this gel formulation is its thermoreversible property. The transition from the liquid state at room temperature to the gel state at body temperature is highly desirable for a topical microbicide because when applied on rough biological surfaces, such as the vaginal or anorectal epithelia, the gel penetrates well into the smallest irregularities, forming a good physical barrier against infectious agents. A common problem associated with the use of vaginal products is that they are messy and may leak out from the vagina. However, because of the negative thermorheological behaviour of this gel, it gels quickly after its intravaginal application and adheres strongly to the mucosa so that the gel should not run out from the vagina and should stay in place during sexual intercourse. Being water-soluble, the gel facilitates the preparation of the final product, which contains microbicides, and may facilitate the industrial development of this product, because it is often difficult to mix chemicals with gelified polymers.

Research has recently shown that the incorporation of nonoxynol-9 into the thermoreversible gel markedly reduced the toxicity of the spermicide/microbicide to human cervical and colon epithelial cells (60). Moreover, studies performed in rabbits have shown that daily intravaginal application of nonoxynol-9 (125 mg total dose) for 14 days was very toxic to the vaginal and cervical mucosae as evidenced by the presence of bleeding, irritation, epithelial disruption, necrosis, accumulation of leukocytes in the submucosa and loss of integrity of the epithelial cells (Figure $2 \mathrm{c}$ ). The presence of important ulcerations and bleeding in the mucosae may favour the entry of HIV or other infectious agents. On the other hand, macroscopic appearance of mucosae of animals treated with the gel alone (Figure $2 \mathrm{~b}$ ) was comparable with that of control animals

\section{REFERENCES}

1. Ebrahim SH, Peterman TA, Zaidi AA, Kamb ML. Mortality related to sexually transmitted diseases in US women, 1973 through 1992. Am J Public Health 1997;87:938-44.

2. Irwin K, Scarlett M, Moseley R. Observations from the CDC. The urgent need for new HIV/STD prevention options for women. J Women's Health 1998;7:1081-6.

3. Crotchfelt KA, Welsh LE, DeBonville D, Rosenstraus M, Quinn TC. Detection of Neisseria gonorrhoeae and Chlamydia trachomatis in genitourinary specimens from men and women by a coamplification PCR assay. J Clin Microbiol 1997;35:1536-40.

4. Fox J. Reports on worldwide HIV paint ever-grimmed picture. ASM News 1998;64:73-4.

5. The Centers for Disease Control and Prevention. Trends in sexual risks behaviors among high school students - United States, 1991-1997. Morb Moral Wkly Rep 1998;47:749-52.

6. Brugha R, Keersmaekers K, Renton A, Meheus A. Genital herpes infection: a review. Int J Epidemiol 1997;26:698-709. treated with buffer (Figure 2a). Of prime importance, the incorporation of the same amount of nonoxynol-9 into the gel markedly reduced the toxicity of this potent spermicide/microbicide for mucosae (Figure 2d). The marked reduction of nonoxynol-9 toxicity when incorporated into the gel may be related to the reduced contact of the spermicide with the mucosae. This is further supported by the fact that the diffusion coefficient of nonoxynol-9 in gel is 2.5 times less than that of nonoxynol-9 in buffer. Thus, the thermoreversible gel may prolong the microbicidal activity of spermicides/microbicides while eliminating their local toxicity and systemic side effects.

Moreover, recent in vitro studies have indicated that a film of the thermoreversible gel on the surface of a membrane acted as an effective physical barrier and prevented infection of susceptible target cells with HIV and HSV-2 (61). The gel is still effective at blocking HSV-2 infection of susceptible cells after being kept for up to six months at room temperature. Furthermore, in vivo efficacy studies have shown that the gel alone prevented the lethal infection of mice with HSV-2 and increased survival compared with control infected mice. These findings, coupled with previous observations, suggest that the gel formulation may be an attractive topical device for the prevention of transmucosal transmission of HIV, HSV-2 and possibly other sexually transmitted pathogens.

\section{CONCLUSIONS}

The dramatic increase in the number of individuals worldwide who are infected with HIV, herpes and other sexually transmitted pathogens underscores the urgent need to develop active products and/or appropriate delivery systems that reduce the sexual transmission of these pathogens with minimal mucosal irritation, and minimal effects on the vaginal flora and $\mathrm{pH}$. There is great interest in the development of novel compounds to reduce the transmission of HIV, herpes and other sexually transmitted pathogens. However, it should be kept in mind that effective topical microbicides include both effective microbicides and appropriate vehicles to deliver efficiently the active agents. This strategy, complemented with promotion of these topical microbicides, should reduce the spread of STDs and especially HIV. The impact of such a preventive tool on public health will, of course, be enormous. Efficient topical microbicides offer new alternatives for individuals who cannot negotiate condom use with their sexual partners.

7. Fleming DT, McQuillan GM, Johnson RE, et al. Herpes simplex virus type 2 in the United States, 1976 to 1994. N Engl J Med 1997;337:1105-11.

8. Fox J. Researchers seek ways to curb mother-to-child HIV transmission. ASM News 1997;63:594-5.

9. Datta P, Embree JE, Kreiss JK, et al. Mother-to-child transmission of human immunodeficiency virus type 1: report from the Nairobi study. J Infect Dis 1994;170:1134-40.

10. Royce RA, Sena A, Cates W Jr, Cohen MS. Sexual transmission of HIV. N Engl J Med 1997;336:1072-8.

11. Miller JM, McGhee JR, Gardner MB. Mucosal immunity, HIV transmission, and AIDS. Lab Invest 1992;68:130-45.

12. Masurier C, Salomon B, Guettari N, et al. Dendritic cells route human immunodeficiency virus to lymph nodes after vaginal or intravenous administration to mice. J Virol 1998;72:7822-9.

13. Fox CH, Hoover S, Curral VR, Bahre HJ, Cottler-Fox M. HIV in infected lymph nodes. Nature 1994;370:256. 
14. Pantaleo G, Graziosi C, Demarest JF, et al. HIV infection is active and progressive in lymphoid tissue during the clinically latent stage of disease. Nature 1993;362:355-8.

15. Embretson J, Zupancic M, Ribas JL, et al. Massive covert infection of helper T lymphocytes and macrophages by HIV during the incubation period of AIDS. Nature 1993;362:359-62.

16. Tacchetti C, Favre A, Moresco L, et al. HIV is trapped and masked in the cytoplasm of lymph node follicular dendritic cells. Am J Pathol 1997;150:533-42.

17. Fauci AS. Multifactorial nature of human immunodeficiency virus disease: implications for therapy. Science 1993;262:1011-8.

18. Laga M, Manoka A, Kivuvu M, et al. Non-ulcerative sexually transmitted diseases as risk factors for HIV-1 transmission in women: results from a cohort study. AIDS 1993;7:95-102.

19. De Wit JBF, Van Griensven GJP, Kok G, Sandfort TGM. Why do homosexual men relapse into unsafe sex? Predictors of resumption of unprotected anogenital intercourse with casual partners. AIDS 1993; 7:1113-8.

20. McCusker J, Stoddard AM, McDonald M, Zapka JG, Mayer KH. Maintenance of behavioral change in a cohort of homosexually active men. AIDS 1992;6:861-8.

21. Elias CJ, Heise LL. Challenges for the development of female-controlled vaginal microbicides. AIDS 1994;8:1-9.

22. Feldblum PJ, Morrison CS, Roddy RE, Cates W Jr. The effectiveness of barrier methods of contraception in preventing the spread of HIV. AIDS 1995;9(Suppl A):S85-93.

23. Claypool LE, Krause P. Development of vaginal microbicides by the CONRAD program: A collaborative effort for research and product development. The 11 th International Conference on AIDS. Vancouver, July 7 to $12,1996$.

24. Elias C. Female-controlled methods to prevent sexual transmission of HIV. The 11 th International Conference on AIDS Vancouver, July 7 to $12,1996$.

25. Short RV. Contraceptives of the future in the light of HIV infection. Aust NZ J Obstet Gynaecol 1994;34:330-2.

26. Stein ZA. HIV prevention: the need for methods women can use. Am J Public Health 1990;80:460-2.

27. Rosenthal SL, Cohen SS, Stanberry LR. Topical microbicides. Current status and research considerations for adolescent girls. Sex Transm Dis 1998:25:368-77.

28. Niruthisard S, Roddy RE, Chutivongse S. The effect of frequent nonoxynol-9 use on the vaginal and cervical mucosa. Sex Transm Dis 1991;18:176-9.

29. Roddy RE, Cordero M, Cordero C, Fortney JA. A dosing study of nonoxynol-9 and genital irritation. Int J STD AIDS 1993:4:165-70.

30. Stafford MK, Ward H, Flanagan A, et al. Safety study of nonoxynol-9 as a vaginal microbicide: evidence of adverse effects. J Acquir Immune Defic Syndr Hum Retrovirol $1998: 17: 327-31$

31. Van Damme L, Niruthisard S, Atisook R, et al. Safety evaluation of nonoxynol-9 gel in women at low risk of HIV infection. AIDS 1998;12:433-7.

32. Martin HL Jr, Stevens CE, Richardson BA, et al. Safety of a nonoxynol-9 vaginal gel in Kenyan prostitutes. Sex Transm Dis $1997: 24: 279-83$

33. Goeman J, Ndoye I, Sakho LM, et al. Frequent use of menfegol spermicidal vaginal foaming tablets associated with a high incidence of genital lesions. J Infect Dis 1995;171:1611-4.

34. Klebanoff SJ. Effects of the spermicidal agent nonoxynol-9 on vaginal microbial flora. J Infect Dis 1992;165:19-25.

35. McGroarty JA, Chung S, Reid G, Bruce AW. Influence of the spermicidal compound nonoxynol-9 on the growth and adhesion of urogenital bacteria in vitro. Curr Microbiol 1990;21:219-23.

36. McGroarty JA, Tomeczek L, Pond DG, Reid G, Bruce AW. Hydrogen peroxide production by Lactobacillus species: correlation with susceptibility to the spermicidal compound nonoxynol-9. J Infect Dis 1992;165:1142-4.

37. Reid G, McGroarty JA, Tomeczek L, Bruce AW. Identification and plasmid profiles of Lactobacillus species from the vagina of 100 healthy women. FEMS Immunol Med Microbiol 1996;15:23-6.

38. Richardson BA, Martin HLJ, Stevens CE, et al. Use of nonoxynol-9 and changes in vaginal lactobacilli. J Infect Dis 1998:178:441-5

39. Rosenstein IJ, Stafford MK, Kitchen VS, Ward H, Weber JN,
Taylor-Robinson D. Effect on normal vaginal flora of three intravaginal microbicidal agents potentially active against human immunodeficiency virus type 1 . J Infect Dis 1998:177:1386-90

40. Chermann JC, Barré-Sinoussi F, Hénin Y, Maréchal V. HIV inactivation by a spermicide containing benzalkomium chloride. AIDS Forsch 1987;2:85-6

41. Hicks DR, Martin LS, Gethell IP, et al. Inactivation of HTLV-III-LAV-infected cultures of normal human lymphocytes by nonoxynol-9 in vitro. Lancet 1985;ii:1422-3.

42. Judson FN, Ehret JM, Bodin GF, Levin MJ, Rietmeijer CAM. In vitro evaluations of condoms with and without nonoxynol-9 as physical and chemical barriers against Chlamydia trachomatis, herpes simplex virus type 2 , and human immunodeficiency virus. Sex Transm Dis 1989;16:51-6.

43. Singh B, Posti B, Cutler JC. Virucidal effect of certain chemical contraceptives in type 2 herpesvirus. Am J Obstet Gynecol 1976:126:422-5

44. Wainberg MA, Bleau G. Effects of benzalkonium chloride on the human immunodeficiency virus (HIV-1) and other infectious agents. Arch AIDS Res 1987;1:57-67.

45. Wainberg MA, Spira B, Bleau G, Thomas R. Inactivation of human immunodeficiency virus type 1 in tissue culture fluid and in genital secretions by the spermicide benzalkonium chloride. J Clin Microbiol 1990;28:156-8

46. Benes S, McCormack WM. Inhibition of growth of Chlamydia trachomatis by nonoxynol-9 in vitro. Antimicrob Agents Chemother 1985;27:724-6.

47. Kelly JP, Reynolds RB, Stagno S, Louv WC, Alexander WJ. In vitro activity of the spermicide nonoxynol-9 against Chlamydia trachomatis. Antimicrob Agents Chemother 1985;27:760-2.

48. Jennings $\mathrm{R}$, Clegg A. The inhibitory effect of spermicidal agents on replication of HSV-2 and HIV-1 in vitro. J Antimicrob Chemother 1993;32:71-82.

49. Malkovsky M, Newell A, Dalgleish AG. Inactivation of HIV by nonoxynol-9. Lancet $1988 ; \mathrm{i}: 645$.

50. Zekeng L, Feldblum PI, Oliver RM, Kaptue L. Barrier contraceptive use and HIV infection among high-risk women in Cameroon. AIDS 1993:7:725-31.

51. Kreiss J, Ngugi E, Holmes K, et al. Efficacy of nonoxynol-9 contraceptive sponge use in preventing heterosexual acquisition of HIV in Nairobi prostitutes. JAMA 1992;268:477-82.

52. Hira SK, Feldblum PJ, Kamanga J, Mukelabai G, Weir SS, Thomas JC. Condom and nonoxynol-9 use and the incidence of HIV infection in serodiscordant couples in Zambia. Int I STD AIDS 1997;8:243-50.

53. Roddy RE, Zekeng L, Ryan KA, Tamoufé U, Weir SS, Wong EL. A controlled trial of nonoxynol-9 film to reduce male-to-female transmission of sexually transmitted diseases. N Engl J Med 1998;339:504-10.

54. McClure DA, Edelman DA. Worldwide method effectiveness of the Today® vaginal contraceptive sponge. Adv Contracept 1985; 1:305-11

55. Larkin M. Easing the way to safer sex. Lancet 1998;351:964.

56. Mayer K, Peipert J, Fleming T, et al. BufferGel: Results of the first phase I study of a novel vaginal microbicide. 12th World AIDS Conference. Geneva, June 28 to July 3, 1998.

57. Rusconi S, Moonis M, Merrill DP, et al. Naphthalene sulfonate polymers with CD4-blocking and anti-human immunodeficiency virus type 1 activities. Antimicrob Agents Chemother 1996:40:234-6

58. Wright A, Rosenstein I, Poulter L, et al. Safety and tolerability of PRO 2000 gel: A potential vaginal virucide. 5th Conference on Retroviruses and Opportunistic Infections. Chicago, January 31 to February 4, 1998

59. Profy AT, Sonderfan AJ, Bourne N, et al. PRO 2000 gel, a potential topical microbicide for HIV prevention, can block infection by other sexually transmitted disease pathogens. 12 th World AIDS Conference. Geneva, June 28 to July 3, 1998.

60. Gagné N, Cormier H, Omar RF, et al. Protective effect of a thermoreversible gel against the toxicity of nonoxynol-9. Sex Transm Dis 1999;26:177-83.

61. Bergeron MG, Gagné N, Désormeaux A, et al. Efficacy of a gel formulation to prevent the transmission of pathogens causing sexually transmitted diseases. 12th World AIDS Conference. Geneva, June 28 to July 3, 1998. 


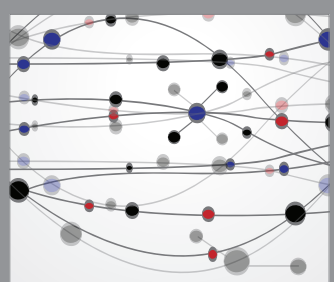

The Scientific World Journal
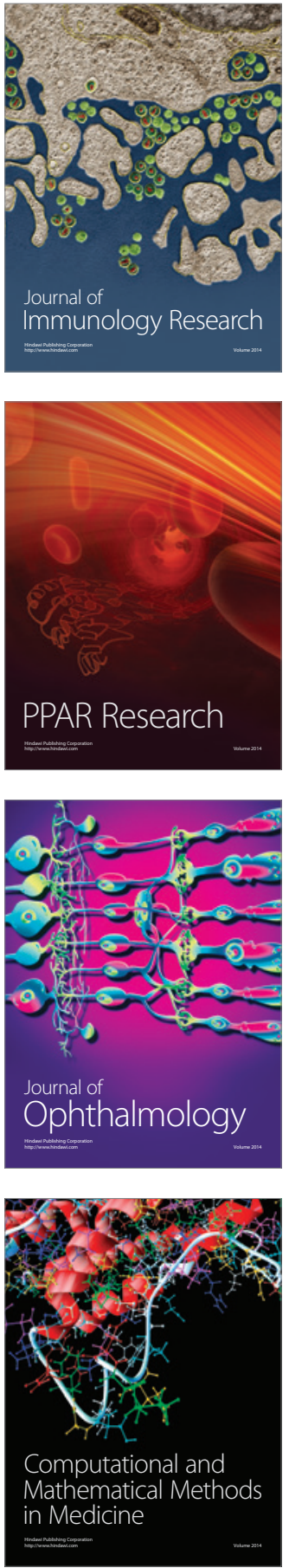

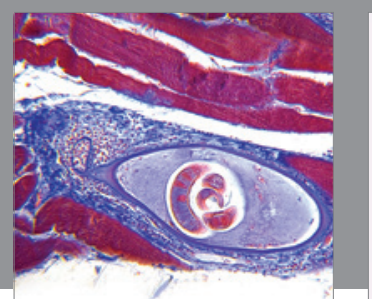

Gastroenterology Research and Practice

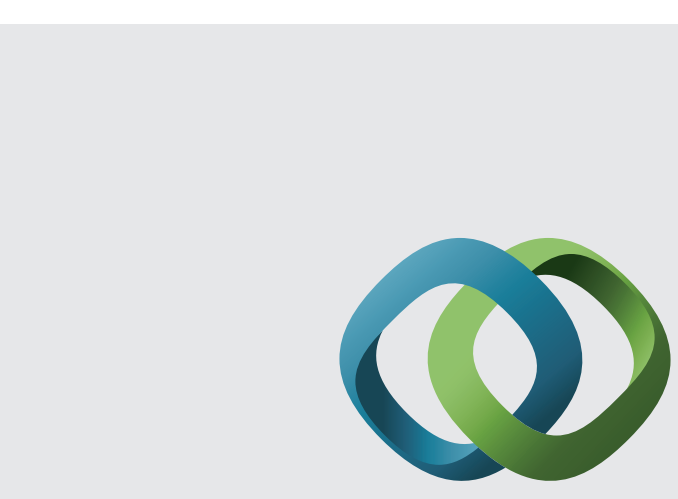

\section{Hindawi}

Submit your manuscripts at

http://www.hindawi.com
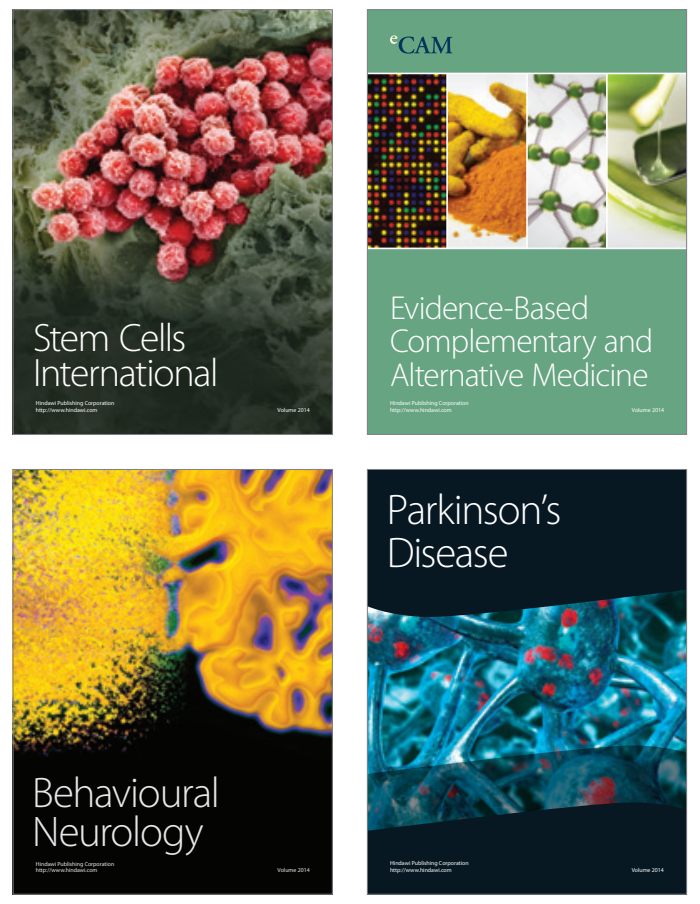
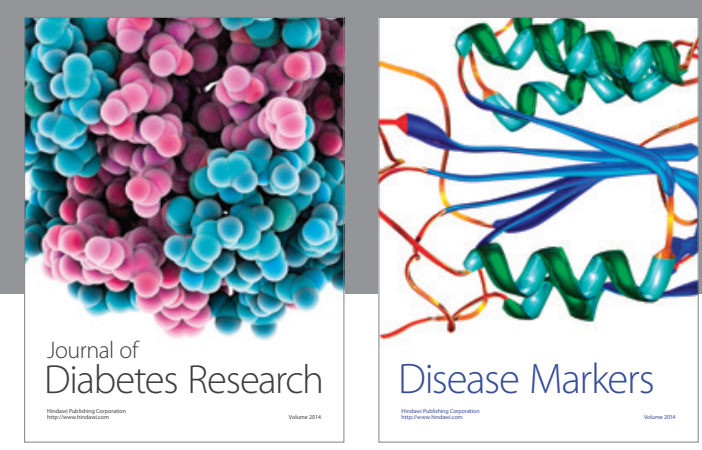

Disease Markers
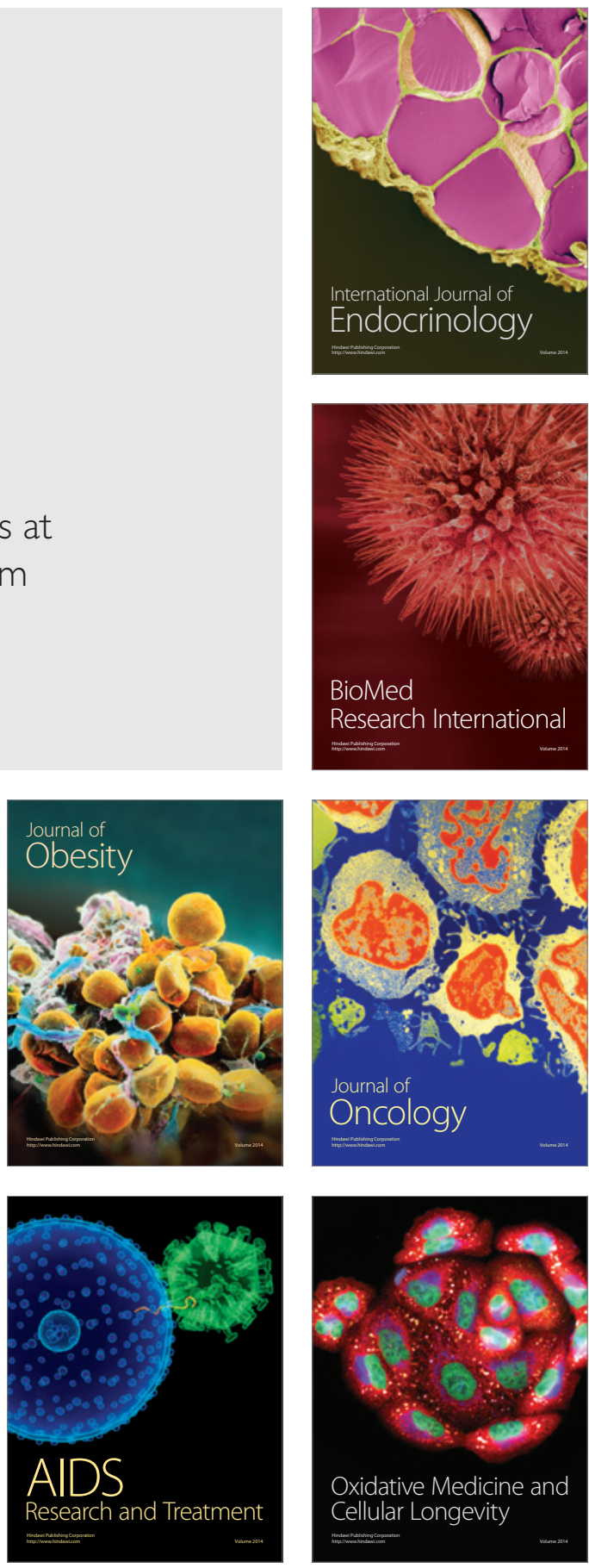